\title{
ARTIGO CIENTIIFICO
}

\section{Aspectos fisiológicos do feijão-caupi e crescimento de tiririca (Cyperus rotundus L.) sob competição em solo compactado}

\section{Physiological Characters of Cowpea and Growth of nut grass (Cyperus rotundus L.) under competition in the soil compressive}

\author{
Edvaldo Nunes da Silva Terceiro ${ }^{1}$, Uriel Calisto Moura Pessôa $a^{2}$, Anielson dos Santos Souza ${ }^{3}$, Alberto de Andrade Soares \\ Filho $^{4}$, Thiago Alves Pimenta ${ }^{5}$
}

\begin{abstract}
Resumo - Vários fatores estão envolvidos na interferência das plantas daninhas sobre as culturas e os aspectos fisiológicos ainda são pouco estudados. Assim, objetivou-se avaliar a interferência de diferentes populações de Cyperus rotundus L. e da compactação do solo nos caracteres fisiológicos do feijão-caupi [Vigna unguiculata (L.) Walp] e na fenologia de $C$. rotundus. $\mathrm{O}$ experimento foi realizado em casa de vegetação no Centro de Ciências e Tecnologia Agroalimentar da Universidade Federal de Campina Grande, CCTA/UFCG, Campus de Pombal-PB. As unidades experimentais foram compostas por vasos com capacidade de 6 litros. Utilizou-se o delineamento inteiramente casualizado com tratamentos distribuídos em esquema fatorial 3 x 2, sendo os fatores três populações de $C$. rotundus $(0,2$ e 3 tubérculos por vaso) e dois níveis de compactação (solo sem compactação e solo com subsuperfície compactada artificialmente), com quatro repetições. Foram coletados os dados de: taxa de assimilação de $\mathrm{CO}_{2}\left(\mu \mathrm{mol} \mathrm{m} \mathrm{m}^{-2} \mathrm{~s}^{-1}\right)$, transpiração $\left(\mathrm{mmol} \mathrm{de} \mathrm{H}_{2} \mathrm{O} \mathrm{m}^{-2} \mathrm{~s}^{-1}\right)$, condutância estomática $\left(\mathrm{mol} \mathrm{de} \mathrm{H}_{2} \mathrm{O} \mathrm{m}^{-2} \mathrm{~s}^{-1}\right)$ e concentração interna de $\mathrm{CO}_{2}$, com um analisador de gás infravermelho - IRGA LCpro (Infra-red Gas Analyzer). Com relação a Cyperaceae, foram coletados os seguintes dados: produção de fitomassa fresca e seca e relação raiz/parte aérea, número de tubérculos por vaso, produção diária de tubérculos e produção de tubérculos por unidade plantada; os quais foram submetidos à análise da variância e teste de médias, quando necessário. A presença de $C$. rotundus, reduziu a fotossíntese líquida do feijãocaupi de forma mais intensa do que a compactação do solo. C. rotundus expressou notável capacidade de reprodução vegetativa.
\end{abstract}

Palavras-chave: Vigna unguiculata (L.) walp, planta daninha., trocas gasosas

\begin{abstract}
Several factors are involved in weed interference on crops and physiological aspects are still studied. Thus, it aimed to evaluate the effect of different populations of Cyperus rotundus L. and soil compaction in the physiological characters of cowpea [Vigna unguiculata (L.) Walp] and the phenology of C. rotundus. The experiment was conducted in a greenhouse in the Science and Technology Center Agrifood the Federal University of Campina Grande, CCTA/UFCG, Campus de PombalPB, Brazil. The experimental were composed of pots with 6 liters capacity. We used a completely randomized design experimental with treatments distributed in a factorial $3 \times 2$, with factors three populations of C. rotundus ( 0,2 and 3 tubers per pot) and two compression levels (soil without compaction and soil compacted subsurface artificially) with four replications. Were collected data from $\mathrm{CO}_{2}$ assimilation rate $\left(\mu \mathrm{mol} \mathrm{m} \mathrm{m}^{-2} \mathrm{~s}^{-1}\right)$, transpiration $\left(\mathrm{mmol} \mathrm{H} \mathrm{O} \mathrm{m}^{-2} \mathrm{~s}^{-1}\right)$, stomatal conductance (mol $\mathrm{H}_{2} \mathrm{O} \mathrm{m}^{-2} \mathrm{~s}^{-1}$ ) and internal concentration $\mathrm{CO}_{2}$, with an infrared gas analyzer - IRGA LCpro. In the Cyperaceae, were collected the following data: fresh and dry biomass production and ratio root/shoot, number of tubers per pot, daily production of tubers and tuber yield per planted unit; which were submitted to analysis of variance and mean test when necessary. The presence of C. rotundus, reduced the net photosynthesis of cowpea more intensely than soil compaction. C. rotundus expressed remarkable capacity for vegetative reproduction.
\end{abstract}

Key words: Vigna unguiculata (L.) Walp, weed, gas Exchange

\footnotetext{
*Autor para correspondência

Recebido para publicação em 10/01/2016; aprovado em 08/02/2016

${ }^{1}$ Bacharel em Agronomia - UFCG/CCTA - Universidade Federal de Campina Grande, Pombal-PB. E-mail: edvaldoterceiro@ hotmail.com

${ }^{2}$ Graduando em Agronomia - UFCG/CCTA - Universidade Federal de Campina Grande, Pombal-PB. E-mail: uriel.pessoa2@ gmail.com

${ }^{3}$ Eng. Agr. D. Sc., Professor da Unidade Acadêmica de Ciências Agrárias - UFCG/CCTA - Universidade Federal de Campina Grande, Pombal-PB. E-mail: anielson@ccta.ufcg.edu.br

${ }^{4}$ Graduando em Agronomia - UFCG/CCTA - Universidade Federal de Campina Grande, Pombal-PB. E-mail: alberto.asf10@ bol.com.br

${ }^{5}$ Graduando em Agronomia - UFCG/CCTA - Universidade Federal de Campina Grande, Pombal-PB. E-mail: tpimenta62@ gmail.com
} 


\section{INTRODUÇÃO}

O feijão-caupi [Vigna unguiculata (L.) Walp] é uma leguminosa de ciclo curto e ampla distribuição mundial, presente, especialmente, nas regiões tropicais, tendo a África com o seu provável centro de origem (MOUSINHO, 2005). Tal cultura se reveste de grande importância econômica, social e alimentar, pois se constitui em uma das principais fontes de emprego e renda da população rural, e a principal fonte de proteína vegetal para a população do semiárido nordestino onde é consumido diariamente na forma de grãos verdes ou secos em pratos variados, sendo cultivado, predominantemente, nas regiões Norte e Nordeste (FREIRE FILHO et al., 2005).

Muitos especialistas são unânimes em afirmar que o cultivo do feijão-caupi, é uma atividade de fundamental importância para o desenvolvimento agrícola da região Nordeste, tanto no aspecto econômico como nutricional, pois é o alimento básico de grande parte da população do semiárido, exercendo função social no suprimento das necessidades nutricionais da população (TEÓFILO; DUTRA; PITOMBEIRA, 2008). Para tanto, são utilizadas cultivares específicas para cada região, afim de otimizar a produção (Embrapa Meio Norte, 2012).

$\mathrm{Na}$ região nordeste, encontram-se as maiores áreas plantadas, e a cultura desempenha função de destaque socioeconômico pelo grande volume de mão-de-obra que pode gerar no campo e na cidade (CARDOSO, RIBEIRO, 2006; FREIRE FILHO et al., 2005). O estado da Paraíba encontra-se entre os principais produtores nacionais, e o feijão-caupi é cultivado em quase todas as microrregiões, onde detém $75 \%$ das áreas de cultivo com feijão. Contudo, níveis baixos de produtividade têm sido constatados, possivelmente, decorrentes do plantio convencional, sem um devido controle das plantas daninhas, e ausência de um programa de manejo de nutrientes (OLIVEIRA et al., 2003).

A produtividade média nacional é da ordem de $822 \mathrm{~kg} \mathrm{ha}^{-1}$ (CONAB, 2008), o que está aquém do potencial produtivo da cultura, considerando os valores reportados em literatura especializada. Historicamente, tal cultura sempre apresentou baixa produtividade, devido às condições de cultivos com pouca adoção de tecnologias apropriadas, precipitação pluvial irregular e controle inadequado das plantas daninhas, sendo estas, responsáveis, pela redução da fotossíntese líquida e menor condutância estomática, o que em última análise pode reduzir o dossel da cultura e a captação de fotoassimilados, com reflexos negativos na produtividade.

Neste sentido, as plantas daninhas constituem um dos fatores que mais influenciam o crescimento e o desenvolvimento do feijão-caupi, pois competem por luz, nutrientes e água, além de exercerem efeitos alelopáticos elevando o grau de interferência, o que se reflete na redução quantitativa e qualitativa da produção, além de aumentar os custos operacionais de colheita, secagem e beneficiamento dos grãos (FREITAS et al., 2009). A interferência reduz a produtividade, por comprometer o processo fotossintético, além de prejudicar a absorção e assimilação de $\mathrm{CO}_{2}$ atmosférico, bem como o uso de água e nutrientes. A interferência faz com que ocorra, disputa por água, luz e nutrientes, diminuindo a disponibilidade para a cultura, com isso a taxa de transpiração (E) decresce como resultado do fechamento dos estômatos. Consequentemente, a concentração intercelular e a disponibilidade de $\mathrm{CO}_{2}$ atingem níveis extremamente reduzidos, prejudicando, sobretudo plantas de metabolismo fotossintético $\mathrm{C}_{3}$, como o feijão-caupi (RAVEN et al., 2001).

Pelo exposto, objetivou-se com o trabalho avaliar o comportamento fisiológico do feijão-caupi, frente a competição com $C$. rotundus L., além da fenologia da espécie infestante em condições de casa de vegetação no semiárido paraibano.

\section{MATERIAL E MÉTODOS}

O trabalho foi realizado em casa de vegetação do Centro de Ciências e Tecnologia Agroalimentar da Universidade Federal de Campina Grande no Campus de Pombal-PB, onde foi utilizado o delineamento experimental inteiramente ao acaso (DIC), com tratamentos arranjados em esquema fatorial $3 \times 2$, totalizando seis tratamentos com quatro repetições. Cada unidade experimental, no total de 24 , foi composta por um vaso com capacidade de seis litros, onde foi instalado, no inicio do ciclo, uma tela tipo sombrite para reduzir a incidência de luminosidade sobre as plantas e, semanalmente, foi uma mudança na posição dos vasos, visando reduzir possíveis efeitos de local.

Para a montagem do experimento foram coletados em área agrícola infestada com $C$. rotundus, na zona rural do município de Pombal cem tubérculos da espécie, os quais foram levados ao laboratório de Fitotecnia da UAGRA/CCTA, lavados em água corrente e semeados em bandeja plástica utilizando-se como substrato areia franca, com o intuito de se verificar a viabilidade dos tubérculos antes do semeio definitivo.

Para enchimento dos vasos utilizou-se substrato composto por $90 \%$ de solo peneirado e seco ao ar com textura média e $10 \%$ de esterco de curral curtido, a essa mistura foi adicionado o equivalente a $10 \%$ da massa do substrato de água por ocasião da homogeneização do substrato. A massa unitária de cada vaso foi de 170 gramas e após enchidos apresentaram massa média de 5.830 gramas, de acordo com teste realizado previamente.

A semeadura do feijão-caupi e plantio da tiririca ocorreram concomitantemente em cada unidade experimental. Foram postas por vaso quatro sementes de feijão caupi, sendo realizado o desbaste, 15 dias após a emergência das plântulas, cortando-se as plantas rente ao solo de modo que permanecessem duas plantas por vaso. Já os tubérculos de $C$. rotundus, selecionados previamente, foram distribuídos ao número de dois ou três por vaso de acordo com tratamento.

Foram feitas regas diárias, com o equivalente a $8 \%$ da massa do substrato, o que correspondeu aproximadamente a $452 \mathrm{~mL}$ de água. No decorrer do experimento verificou-se um fraco crescimento das plantas de feijão, sobretudo nos tratamentos infestados com tiririca, e como havia uma limitação de recursos disponíveis devido ao pequeno tamanho do vaso, realizaram-se regas periódicas com o uso de solução nutritiva para garantir melhor crescimento das plantas, tal solução foi preparada no Laboratório de Fisiologia Vegetal da UAGRA/CCTA/UFCG.

O cultivar de feijão utilizado foi o BR 17 Gurguéia desenvolvido pela Embrapa Meio-Norte em Teresina - PI, e 
possui as seguintes características: hábito de crescimento indeterminado com porte enramador, folha globosa, período médio de floração de 43 a 52 dias após o plantio, ciclo de 75 dias em média, flor com coloração roxa destacada pelo estandarte e pela quilha, quando imatura a vagem possui coloração verde e quando seca amarela, com comprimento médio de $17 \mathrm{~cm}$ e 15 sementes por vagem, o peso médio de 100 sementes é de $12,5 \mathrm{~g}$, as quais possuem coloração esverdeada (EMBRAPA, 2008).

Nos tratamentos com o solo da sub superfície compactado, a camada correspondente foi obtida mediante a compactação mecânica com o uso de um cilindro de PVC com diâmetro semelhante ao diâmetro do vaso, a saber: 150 $\mathrm{mm}$ e altura compactada de $30 \mathrm{~mm}$. A massa compactada correspondeu a $20 \%$ da massa total de substrato, que foi de 1.132 gramas.

Com isso, o volume de substrato compactado foi de $495,40 \mathrm{~cm}^{3}$, e a densidade da camada compactada foi de 2,28 $\mathrm{g} \mathrm{cm}^{3}$, considerando-se como densidade, a relação entre a massa de solo e o volume do cilindro. A camada de substrato compactado foi colocada a $7 \mathrm{~cm}$ de altura em relação ao fundo do vaso e a $10 \mathrm{~cm}$ de profundidade em relação a superfície do vaso.

Além das regas como tratos culturais, ainda realizou-se, durante a condução do experimento, aplicações de defensivos agrícolas devido à ocorrência de cochonilhas e pulgões quando o feijão estava no estádio V3, sendo utilizado inseticida a base de deltamethrin 25 EC. Também foi necessária a aplicação de fungicida a base de clorotalonil (isoftalonitrila) oxicloreto de cobre (inorgânico) formulado como pó molhável, para o controle de Rizoctonia spp.

Por duas vezes foi necessária a aplicação ferro EDTA na quantidade de $6 \mathrm{ml}$ por vaso, pois apesar da solução nutritiva utilizada para regar as plantas possuir tal nutriente, a presença de sintomas de deficiências foi comum em todos os tratamentos. Vale informar que, após a aplicação os sintomas de clorose internerval desapareciam em poucos dias.

Foi realizada, análise fisiológica, com o apoio da equipe do Laboratório de Fisiologia Vegetal do CCTA/UFCG, utilizando um analisador de gás infravermelho - IRGA LCpro (Infra-red Gas Analyzer) com fonte de luz constante de 1.200 $\mu \mathrm{mol}$ de fótons $\mathrm{m}^{-2} \mathrm{~s}^{-1}$, que dá suporte as medições de trocas gasosas na cultura, essa análise foi feita, nas plantas que apresentavam suas folhas completamente formadas, sendo realizada duas leituras por parcela. As características analisadas foram as seguintes: taxa de assimilação de $\mathrm{CO}_{2}$ $\left(\mu \mathrm{mol} \mathrm{m}^{-2} \mathrm{~s}^{-1}\right)$; transpiração (mmol de $\left.\mathrm{H}_{2} \mathrm{O} \quad \mathrm{m}^{-2} \mathrm{~s}^{-1}\right)$; condutância estomática (mol de $\mathrm{H}_{2} \mathrm{O} \mathrm{m}^{-2} \mathrm{~s}^{-1}$ ) e concentração interna de $\mathrm{CO}_{2}\left(\mu \mathrm{mol} \mathrm{m} \mathrm{m}^{-2} \mathrm{~s}^{-1}\right)$.

Aos 81 dias após a semeadura, as unidades experimentais foram levadas ao Laboratório de Fitotecnia da UAGRA/CCTA/UFCG, para a coleta final dos dados relativos às seguintes características: 1) produção de fitomassa fresca e seca da tiririca e relação raiz/parte aérea; 2) número de tubérculos por vaso; 3) produção diária de tubérculos, e 4) produção de tubérculos por unidade semeada.
Para tanto, as plantas foram separadas em parte aéreas e raízes. Após o corte da parte aérea retirou-se o conteúdo do vaso de maneira indeformada. Tal material foi colocado em balde com capacidade para 10 litros e umedecido até separação das raízes, estolões e tubérculos contidos no substrato.

Em seguida o material foi colocado em sacos de papel e pesados em balança com precisão de 0,5 gramas para a obtenção da fitomassa fresca, sendo os valores da parte aérea, das raízes e dos tubérculos expressos em gramas. Posteriormente as amostras foram postas para secar em estufa de circulação de ar a $65^{\circ} \mathrm{C}$, até atingir massa constante para obtenção da fitomassa seca através de pesagem. A partir da obtenção da fitomassa seca da parte subterrânea (raízes, tubérculos e estolões) e da parte aérea, determinou-se a relação raiz/ parte aérea.

O número de tubérculos por vaso foi obtido por contagem após a separação das demais estruturas subterrâneas de $C$. rotundus. Determinou-se a produção diária de tubérculos, dividindo-se o número total de tubérculos pelo número de dias decorridos da semeadura ao término do experimento, e o número de tubérculos por unidade de tubérculo semeada pela razão entre o número total obtido e o número semeado, que foi de dois e três conforme o tratamento.

Os dados coletados foram submetidos a uma análise da variância pelo Teste $F$, quando se verificou efeito significativo nos parâmetros da análise, realizou-se a separação das médias pelo teste de Tukey ( $\mathrm{p} \leq 5 \%$ ), com exceção do fator densidade do solo por conter apenas duas médias. A análise estatística foi realizada com o auxílio do programa computacional para análises estatísticas SAEG v.9.1.

\section{RESULTADOS E DISCUSSÃO}

Observando-se os resumos das análises das variâncias para os dados de fotossíntese líquida (FS), concentração intercelular de $\mathrm{CO}_{2}(\mathrm{Ci})$, transpiração (E) e condutância estomática (gs) do feijão-caupi cultivado na presença e na ausência de solo compactado e de C. rotundus, verificou-se efeito significativo dos efeitos principais e das interações em todas as características fisiológicas estudadas em nível de $1 \%$ de probabilidade pelo teste $\mathrm{F}$ (Tabela 1 ).

No desdobramento da interação dupla significativa $\mathrm{T} x$ $\mathrm{C}$ presença de tiririca e solo compactado, em teste de médias para os dados de fotossíntese liquida (A) do feijão-caupi, constatou-se ao se estudar o efeito da população de planta daninha dentro de cada condição de solo, que em condições de compactação, a presença de $C$. rotundus reduziu significativamente a fotossíntese líquida da cultura quando foram semeados três tubérculos por vaso, já em solo sem compactação, a redução também ocorreu com o semeio de dois tubérculos por vaso (Tabela 2). 
Tabela 1. Resumos das análises das variâncias para os dados de fotossíntese líquida (A), Concentração intercelular de $\mathrm{CO}_{2}$ (Ci), transpiração (E) e condutância estomática (gs) do feijão-caupi

\begin{tabular}{cccccc}
\hline \hline Fontes de variação & GL & \multicolumn{4}{c}{ Quadrados Médios } \\
& & FS & CI & TI & GS \\
\hline População de Tiririca (T) & 2 & $458078000 * *$ & $1063376 * *$ & $46247550 * *$ & $134522 * *$ \\
Compactação (C) & 1 & $216817800 * *$ & $5686485 * *$ & $35482820 * *$ & $64293 * *$ \\
T x C & 2 & $257790900 * *$ & $6906357 * *$ & $34146820 * *$ & $78707 * *$ \\
Resíduo & 18 & 12409000 & 3089505 & 1522472 & -606 \\
Total & 23 & - & - & - & - \\
\hline \hline
\end{tabular}

$(* *),(*),(\mathrm{ns})$ significativos a $1 \%, 5 \%$ e não significativo respectivamente, pelo teste $\mathrm{F}$.

Tais resultados são coerentes, pois, sabe-se que a competição entre cultura e planta daninha se dá em diferentes níveis e por diferentes recursos do substrato ecológico, e no caso em estudo, é fato que a espécie infestante propiciou um menor crescimento do feijão-caupi, talvez pelo consumo de recursos como luz e nutrientes que seriam destinados a cultura, em situações dessa natureza o estabelecimento de um menor aparato fotossintético, bem como de um menor índice de área foliar pela cultura, contribuem para a obtenção de menores valores de fotossíntese líquida total, devido presença da planta daninha.

O feijão-caupi é planta com certa rusticidade, especialmente quando comparada a outras espécies cultivadas, pode assim ter mantido os níveis adequados de fotossíntese líquida para a manutenção de uma estrutura morfológica mínima.

$\mathrm{Na}$ comparação entre as médias de tratamentos com camada de solo compactada ou sem compactação, dentro de cada nível populacional de planta daninha, verificou-se redução da fotossíntese líquida total apenas na ausência de $C$. rotundus (nível zero), onde as plantas cultivadas apresentaram em solo sem compactação notável valor para a característica em apreço, o qual foi superior estatisticamente aos valores médios observados nos demais tratamentos.

Tabela 2. Fotossíntese líquida do feijão-caupi cv. BR 17 Gurguéia, em solo compactado e infestado com $C$. rotundus L.

\begin{tabular}{ccccc}
\hline \hline \multirow{2}{*}{ Compactação } & \multicolumn{4}{c}{ Número de tubérculos por vaso } \\
\cline { 2 - 4 } & 0 & 2 & 3 & Médias \\
\cline { 2 - 5 } & $6.535 \mathrm{Ab}$ & $4.455 \mathrm{Aa}$ & $1.591 \mathrm{Ba}$ & $4.193 \mathrm{~b}$ \\
Sem & $20.334 \mathrm{Aa}$ & $1.574 \mathrm{Ba}$ & $3.707 \mathrm{Ba}$ & $8.538 \mathrm{a}$ \\
\hline Médias & $13.434 \mathrm{~A}$ & $3.014 \mathrm{~B}$ & $2.649 \mathrm{~B}$ & 6.365 \\
\hline \hline Médias
\end{tabular}

Médias seguidas de letras iguais maiúsculas nas linhas e minúsculas nas colunas, não diferem estatisticamente entre si pelo teste de Tukey a $5 \%$ de probabilidade.

No que se refere à concentração intercelular de $\mathrm{CO}_{2}$ na cultura, frente a infestação com $C$. rotundus, verificou-se comportamento semelhante nas duas condições de solo, e a presença da Cyperaceae estabelecida a partir do semeio de dois ou três tubérculos, propiciou uma menor concentração intercelular de $\mathrm{CO}_{2}$, e por conseguinte, menor taxa fotossintética, menor área foliar e menor crescimento do vegetal, conforme discutido anteriormente. Silva e Silva (2007) reportam que na maioria dos casos a competição por $\mathrm{CO}_{2}$, pode ser considerada desprezível, todavia, no presente estudo, o elevado grau de interferência da planta daninha sobre a cultura pode ter levado o caupi a reduzir a condutância estomática, e suas trocas gasosas a fim de garantir menor perda de água já que o ambiente estava infestado por plantas daninhas e a água aplicada nos vasos, era possivelmente, objeto de intensa disputa. Supõem-se, portanto, que a cultura sendo considerada portadora de plasticidade ambiental, conforme salientam Mendes et al (2007), se adaptou a condição de estresse, mas teve com isso, o seu crescimento normal prejudicado.

Estudando o efeito da compactação dentro dos níveis da plana daninha, constatou-se maiores valores de concentração intercelular de $\mathrm{CO}_{2}$, nas plantas de feijão-caupi cultivadas em solo sem compactação, havendo diferença estatística, entre as médias dos tratamentos com zero e dois tubérculos de $C$. rotundus (Tabela 3 ).

Tabela 3. Concentração intercelular de $\mathrm{CO}_{2}$ do feijão-caupi cv. BR 17 Gurguéia, em compactado e infestado com $C$. rotundus L.

\begin{tabular}{|c|c|c|c|c|}
\hline \multirow{3}{*}{ Compactação } & \multicolumn{3}{|c|}{ Número de tubérculos por vaso } & \multirow{3}{*}{ Médias } \\
\hline & 0 & 2 & 3 & \\
\hline & \multicolumn{3}{|c|}{---1 } & \\
\hline Com & $84.189 \mathrm{Ab}$ & $25.032 \mathrm{Bb}$ & $25.952 \mathrm{Ba}$ & $57.221 b$ \\
\hline Sem & 393.708 Aa & $61.523 \mathrm{Ba}$ & $44.981 \mathrm{Ba}$ & $154.574 \mathrm{a}$ \\
\hline Médias & $238.949 \mathrm{~A}$ & $43.278 \mathrm{~B}$ & $35.467 \mathrm{~B}$ & 105.898 \\
\hline
\end{tabular}

Médias seguidas de letras iguais maiúsculas nas linhas e minúsculas nas colunas, não diferem estatisticamente entre si pelo teste de Tukey a 5\% de probabilidade.

Tais resultados servem para reforçar a hipótese de que o recurso da água se tornou escasso no solo, tanto pela alta competição interespecífica, que reduz a quantidade de água para cada indivíduo presente no meio, como pela 
compactação do solo que pode ter limitado a expansão das raízes do feijão-caupi e, por conseguinte o acesso pleno a umidade do substrato, em quantidade tal que, permitisse uma abertura adequada de seus estômatos e com isso maior captação de $\mathrm{CO}_{2}$.

Pelo teste de Tukey aplicado as médias dos dados do componente fisiológico condutância estomática (gs), observou-se superioridade estatística da média do tratamento sem a presença da planta daninha e daquela obtida no tratamento com o semeio de dois tubérculos, em relação à média obtida com o semeio de três tubérculos no solo com camada compactada, já na ausência da compactação a média do tratamento sem planta daninha foi sobejamente superior às demais médias, todavia as médias dos tratamentos com dois ou três tubérculos não diferiram estatisticamente (Tabela 4). Sendo assim pode-se entender que, a presença de $C$. rotundus, no ambiente de cultivo prejudica a cultura independente de sua população, especialmente se o espaço a ser explorado for limitado.

Outro fato a ser considerado é que com a redução da condutância estomática na cultura do feijão-caupi, que reconhecidamente expressa tal característica em condições de estresse como um mecanismo de adaptação, ocorre igualmente uma menor captação de $\mathrm{CO}_{2}$, para a formação de esqueletos de carbono a serem utilizados na composição de compostos orgânicos nas células vegetais, os quais são de suma importância para um adequado crescimento. Tais resultados, evidenciam sobremaneira que o menor crescimento da cultura pode estar relacionado ao custo adaptativo à condição de estresse biótico imposto, e que o estudo dos componentes fisiológicos auxilia a revelar a forma com que a cultura responde internamente a tais condições.

Na comparação das médias dos dados da característica condutância estomática dos tratamentos com e sem compactação dentro de cada nível de $C$. rotundus, verificouse superioridade estatística do tratamento sem compactação apenas no nível zero de C. rotundus (Tabela 4). Diante disso, infere-se que, tanto na presença como na ausência da planta daninha, pode ocorrer redução na condutância estomática do feijão-caupi, apesar de os danos decorrentes da interferência das plantas daninhas serem maiores. Pois como salientam Silva e Silva (2007) no ambiente agrícola os vegetais estão sujeitos à competição por recursos e condições, e os recursos em quantidades limitadas auxiliam no estabelecimento de um elevado grau de interferência, notadamente se a condição de cultivo não for adequada, já que a mesma afeta a utilização dos recursos.

Tabela 4. Condutância estomática do feijão-caupi cv. BR 17 Gurguéia, sob solo compactado e infestado com C. rotundus L.

\begin{tabular}{ccccc}
\hline \hline & \multicolumn{4}{c}{ Número de tubérculos por vaso } \\
\cline { 2 - 5 } Compactação & 0 & 2 & 3 & Médias \\
\cline { 2 - 5 } & $109,44 \mathrm{Ab}$ & $28,31 \mathrm{Aa}$ & $71,74 \mathrm{~b}$ \\
\cline { 2 - 5 } Com & $436,82 \mathrm{Aa}$ & $78,77 \mathrm{Ba}$ & $27,02 \mathrm{Ba}$ & $175,26 \mathrm{a}$ \\
\hline Sem & $273,13 \mathrm{~A}$ & $53,53 \mathrm{~B}$ & $43,83 \mathrm{~B}$ & 123,50 \\
\hline \hline
\end{tabular}

Médias seguidas de letras iguais maiúsculas nas linhas e minúsculas nas colunas, não diferem estatisticamente entre si pelo teste de Tukey a 5\% de probabilidade.

Analisando-se o efeito da compactação do solo e número de tubérculos de $C$. rotundus sobre a transpiração do feijão-caupi, pode-se observar que o comportamento foi semelhante à condutância estomática, e os tratamentos isentos de compactação e plantas daninhas apresentaram maiores valores de transpiração (Tabela 5), sendo condizente com a condutância estomática apresentada pelas plantas de feijão.

Tabela 5. Transpiração do feijão-caupi cv. BR 17 Gurguéia, em compactado e infestado com C. rotundus L.

\begin{tabular}{|c|c|c|c|c|}
\hline \multirow{3}{*}{ Compactação } & \multicolumn{3}{|c|}{ Número de tubérculos por vaso } & \multirow{3}{*}{ Médias } \\
\hline & 0 & 2 & 3 & \\
\hline & \multicolumn{3}{|c|}{ 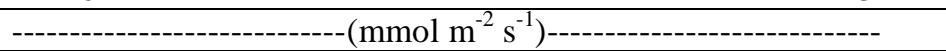 } & \\
\hline Com & $1.485 \mathrm{Ab}$ & $585,26 \mathrm{Aa}$ & $487,29 \mathrm{Aa}$ & $1.059 \mathrm{~b}$ \\
\hline Sem & $8.619 \mathrm{Aa}$ & $1.207 \mathrm{Ba}$ & $1.272 \mathrm{Ba}$ & $3.492 \mathrm{a}$ \\
\hline Médias & $5.052 \mathrm{~A}$ & $896 \mathrm{~B}$ & $879 \mathrm{~B}$ & 2.276 \\
\hline
\end{tabular}

M.276 Aaa------------------mmol m17 Gurguéia, ada pelas plantas de feijão. taram maiores valores de transpiração (Tabela ática do feijão-caupi, apesar de os $\mathrm{d}$

Os resumos das análises das variâncias para os dados de fitomassa fresca da parte aérea, fitomassa fresca de tubérculos e fitomassa fresca de raízes de $C$. rotundus, podem ser observados na Tabela 6, onde verifica-se efeito significativo para os fatores principais, população de tiririca e compactação do solo, apenas para os dados de fitomassa fresca da parte aérea, os quais variaram independentes pelo teste $\mathrm{F}$ em nível de $5 \%$ de probabilidade.

Na separação das médias dos efeitos da compactação do solo e da população de $C$. rotundus, para os dados de fitomassa fresca, observou-se que em solo com camada compactada a Cyperaceae, produziu uma menor quantidade de fitomassa fresca da parte aérea (FFPA) em relação ao solo normal, isto revela que apesar da agressividade da espécie infestante as condições edáficas inapropriadas podem exercer efeito negativo sobre o crescimento do vegetal (Figura 1A).

Comparando-se as médias obtidas nos tratamentos com diferentes populações de $C$. rotundus, verificou-se maior produção de FFPA, no tratamento com maior densidade de planta daninha, o que é coerente, haja vista o semeio de uma maior quantidade de tubérculos por unidade experimental em tal tratamento. Isto evidência, que a maior competição interespecífica e intraespecífica, nesta situação não promoveu a redução na produção de fitomassa fresca da parte aérea (Figura 1B). 
Tabela 6. Resumos das análises das variâncias para os dados de fitomassa fresca da parte aérea (FFPA), fitomassa fresca de tubérculos (FFTU) e fitomassa fresca de raízes (FFR) de tiririca C. rotundus L.

\begin{tabular}{lcccc}
\hline \hline \multirow{2}{*}{ Fontes de variação } & GL & & Quadrados Médios \\
& & FFPA & FFTU & FFR \\
\hline População de Tiririca (T) & 1 & $2849 *$ & $36,21 \mathrm{~ns}$ & $229,67 \mathrm{~ns}$ \\
Compactação (C) & 1 & $2806 *$ & $85,88 \mathrm{~ns}$ & $1309,71 \mathrm{~ns}$ \\
T x C & 1 & $117,45 \mathrm{~ns}$ & $100 \mathrm{~ns}$ & $21,66 \mathrm{~ns}$ \\
\hline Resíduo & 12 & 693,17 & 367,62 & 3043,67 \\
Total & 15 & - & - & - \\
\hline \hline
\end{tabular}

$(*),(\mathrm{ns})$ significativo a 5\% e não significativo respectivamente, pelo teste $\mathrm{F}$.

Figura 1. Produção de fitomassa fresca da parte aérea de tiririca $C$. rotundus L. em função das condições de solo (A) e do número de tubérculos semeados no vaso (B). As médias com letras diferentes nas colunas indicam diferença estatística pelo teste $\mathrm{F}(\mathrm{p} \leq 5 \%)$

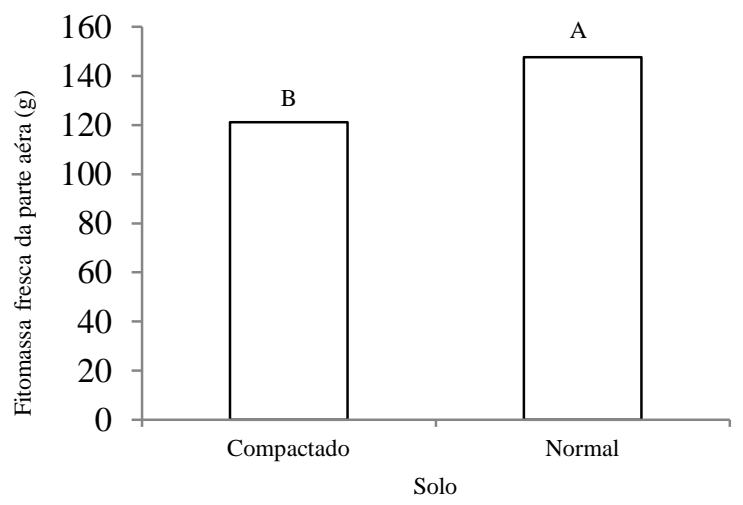

A.

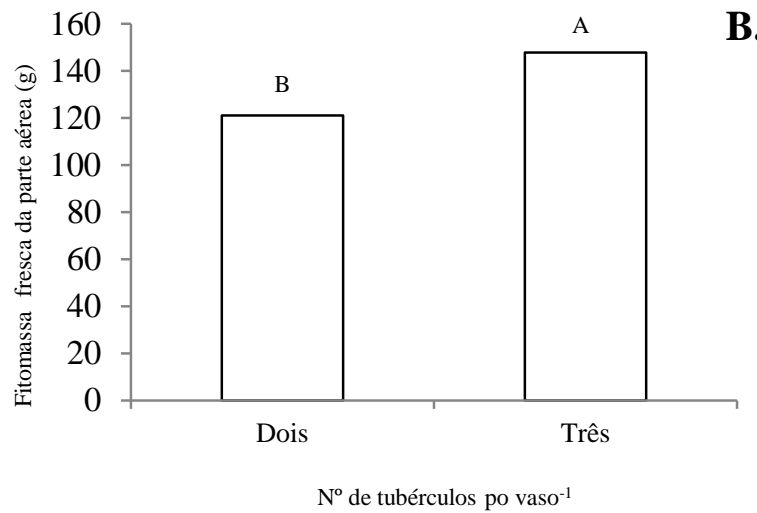

B.

Com relação à produção de fitomassa seca de $C$. rotundus, obteve-se efeito significativo para os fatores população de tiririca para os dados de FSPA, e de compactação do solo nos dados de fitomassa seca de tubérculos e fitomassa seca radicular, bem como para a

interação $\mathrm{T}$ x C, para os dados de fitomassa seca de tubérculos (FSTU) pelo teste $\mathrm{F}$ a $5 \%$ de probabilidade (Tabela 7). Não houve efeito significativo na análise da variância para os dados de relação raiz parte aérea

Tabela 7. Resumos das análises das variâncias para os dados de fitomassa seca da parte aérea (FSPA), fitomassa seca de tubérculos (FSTU), fitomassa fresca de raízes (FSR) e relação raiz/ parte aérea de tiririca C. rotundus L.

\begin{tabular}{lccccc}
\hline \hline \multirow{2}{*}{ Fontes de variação } & GL & \multicolumn{2}{c}{ Quadrados Médios } \\
& & FSPA & FSTU & FSR & RRPA \\
\hline População de Tiririca (T) & 1 & $85,70 *$ & $26,80 \mathrm{~ns}$ & $40,73 \mathrm{~ns}$ & $0,15 \mathrm{~ns}$ \\
Compactação (C) & 1 & $35,31 \mathrm{~ns}$ & $181,50 *$ & $2879 *$ & $2,66 \mathrm{~ns}$ \\
T x C & 1 & $2,74 \mathrm{~ns}$ & $224,02 *$ & $5,27 \mathrm{~ns}$ & $0,10 \mathrm{~ns}$ \\
Resíduo & 12 & 21,41 & 37,42 & 664,06 & 1,75 \\
Total & 15 & - & - & - & - \\
\hline \hline
\end{tabular}

$\left({ }^{* *}\right),(*),(\mathrm{ns})$ significativos a $1 \%, 5 \%$ e não significativo respectivamente, pelo teste $\mathrm{F}$.

Em média a relação raiz parte aérea de $C$. rotundus foi de 3,4, ou seja, para cada grama de fitomassa aérea produzida, foram produzidas 3,4 gramas de fitomassa radicular, composta por raízes, tubérculos e estolões, o que corresponde a um valor $340 \%$ superior a fitomassa aérea, bem superior a relação raiz parte aérea do feijão-caupi, que no presente estudo foi em média de 0,56 , independente do tratamento.

Com tais resultados, fica demonstrado o expressivo crescimento radicular de $C$. rotundus, em relação à cultura estudada e também em ralação ao crescimento de sua parte aérea. O que representa uma característica de agressividade da planta daninha, a qual investe grande parte dos fotoassimilados na produção de estruturas subterrâneas utilizadas para propagação, e também para garantir a exploração de um maior volume de solo e uma rápida ocupação e disseminação do meio edáfico.

$\mathrm{Na}$ comparação das médias dos tratamentos com diferentes populações de $C$. rotundus, para a característica produção de fitomassa seca da parte aérea, constatou-se um maior valor quando foram semeados três tubérculos por vaso, evidenciando-se que tal espécie possui notável capacidade de produção de fitomassa quando em alta densidade, não sofrendo efeito da competição por restrições no ambiente (Figura 2). Cumpre informar que a produção de fitomassa seca da parte aérea de $C$. rotundus, foi cerca de duas vezes a mais do que a do feijão-caupi, o que pode ser justificado, pelo fato de a cultura possuir metabolismo fotossintético $\mathrm{C}_{3}$, enquanto na planta daninha é do tipo $\mathrm{C}_{4}$. 
Figura 2. Produção de fitomassa seca da parte aérea por vaso de tiririca $C$. rotundus L. em função do número de tubérculos semeados. As letras diferentes nas colunas indicam diferença significativa pelo teste $\mathrm{F}(\mathrm{p} \leq 0,05)$

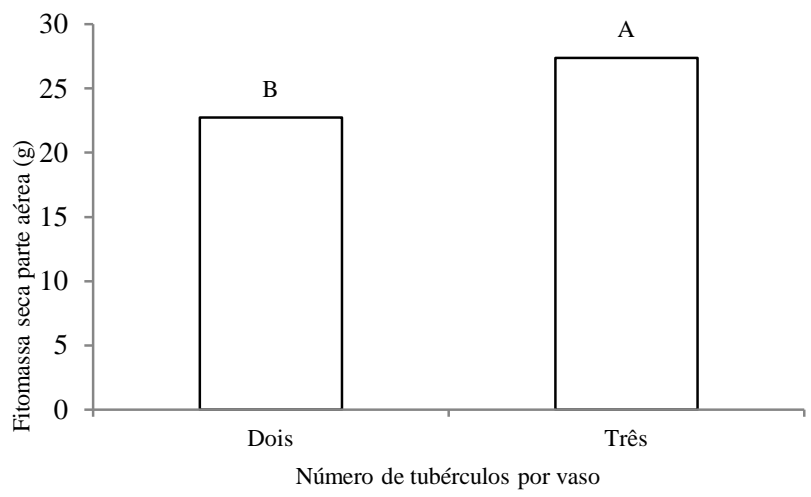

No desdobramento em teste de médias da interação dupla significativa $\mathrm{T}$ x $\mathrm{C}$, para os dados de produção de fitomassa seca de tubérculos, constatou-se que em solo com camada compactada o maior valor de fitomassa de tubérculos foi obtido com o semeio de três unidades por vaso, já em solo sem compactação não houve diferença entre as médias, quando foram semeados dois ou três tubérculos por vaso (Tabela 8).

No tocante ao estudo da condição de solo dentro de cada nível populacional de $C$. rotundus, obteve-se maior produção de fitomassa seca com o semeio de dois tubérculos em solo sem compactação, isto indica que quando o solo não apresenta impedimentos, é possível que haja maior emissão e crescimento tubérculos, o que resulta em maior fitomassa. Quando foram semeados três tubérculos por vaso não houve diferença estatística entre as médias dos tratamentos com e sem compactação do solo (Tabela 8).

Tabela 8. Fitomassa seca de tubérculos de tiririca $C$. rotundus L., em diferentes condições de solo e densidade de semeadura

\begin{tabular}{cccc}
\hline \hline \multirow{3}{*}{ Compactação } & \multicolumn{2}{c}{ Número de tubérculos por vaso } & \\
\cline { 2 - 3 } & \multicolumn{2}{c}{2} & 3 \\
\cline { 2 - 3 } & Médias \\
\cline { 2 - 3 } & ------------ -unidade------------- & \\
\hline Com & $30,60 \mathrm{Bb}$ & $40,67 \mathrm{Aa}$ & $35,64 \mathrm{~b}$ \\
Sem & $44,82 \mathrm{Aa}$ & $39,93 \mathrm{Aa}$ & $42,38 \mathrm{a}$ \\
\hline Médias & 37,71 & 40,30 & 39 \\
\hline \hline
\end{tabular}

Médias seguidas de letras iguais maiúsculas nas linhas e minúsculas nas colunas, não diferem estatisticamente entre si pelo teste de Tukey a 5\% de probabilidade.

Para a produção de fitomassa seca das raízes, verificouse redução significativa em solo compactado em relação ao valor obtido em solo normal, o que se deve possivelmente a restrição física imposta, apesar da agressividade da Cyperaceae (Figura 3). De certo modo, tal resultado é divergente de informações de Silva e Silva (2007), quando reportam que em solo compactado é comum uma maior incidência de plantas daninhas. Todavia, é possível que o grau de compactação seja decisivo para garantir maior ou menor emergência de plantas daninhas. Vale lembrar que se a compactação do solo afeta o crescimento radicular de uma planta daninha, o seu efeito será ainda mais pronunciado sobre a cultura
Figura 3. Produção de fitomassa seca das raízes de tiririca $C$. rotundus L. em função da compactação do solo. As letras diferentes nas colunas indicam diferença significativa pelo teste $\mathrm{F}(\mathrm{p} \leq 0,05)$

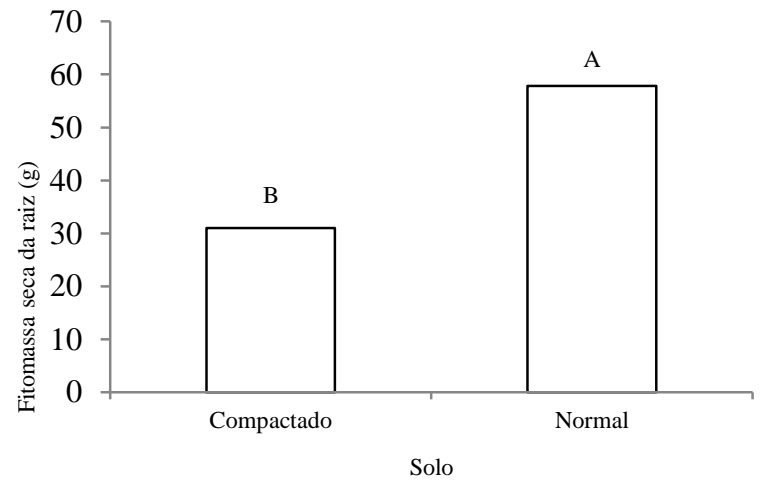

Os dados da produção relativa de fitomassa de $C$. rotundus podem ser observados na Figura 4, a parte aérea foi responsável por aproximadamente $23,51 \%$ do total de fitomassa produzida, independente do tratamento, e o maior valor percentual foi verificado no tratamento onde foram semeados três tubérculos por vaso (T3S1), com 26,25\%. Com relação a participação dos tubérculos na produção total de fitomassa seca o valor médio foi de $36,40 \%$ do total, independente do tratamento e no T3S1 foi onde se obteve o maior valor que correspondeu a 40,61 \%. Já para o conjunto raízes e estolões, o valor médio foi de 40,07 \% em relação ao total produzido; e foi no tratamento T3S0, onde se obteve a maior participação relativa deste componente na produção de fitomassa seca que foi de 46,26\% (Figura 4).

Tem-se, portanto que para a espécie $C$. rotundus, a distribuição e acúmulo de fitomassa se dão na seguinte ordem raízes e estolões > tubérculos > parte aérea, endossando assim, informações de Silva e Silva (2007) ao reportarem que a maior agressividade competitiva da espécie decorre de sua grande produção de propágulos reprodutivos subterrâneos já que a propagação por sementes é considerada de menor importância.

Figura 4. Produção relativa de fitomassa seca de tiririca (C. rotundus L.), nos diferentes tratamentos. T2S0 (solo sem compactação e com o plantio de dois tubérculos de $C$. rotundus L.); T2S1 (solo compactado e com o plantio de dois tubérculos de $C$. rotundus L.); T3S0 (solo sem compactação e com o plantio de três tubérculos de $C$. rotundus L.); T3S1 (solo compactado e com o plantio de três tubérculos de $C$. rotundus $\mathrm{L}$.)

口Parte aérea $\square$ Tubérculos $\square$ Raízes

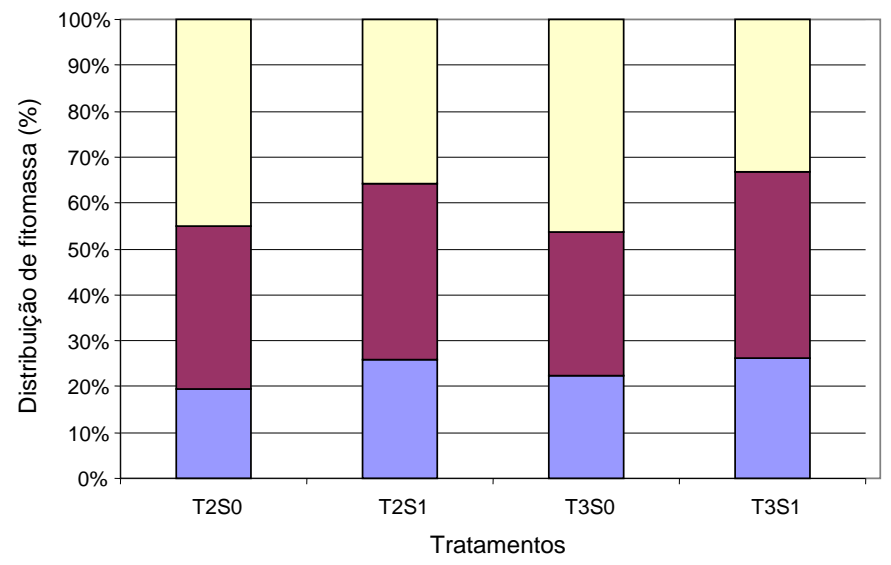


Pelos quadrados médios da análise da variância para os dados de número de tubérculos produzidos por vaso (NTU), produção diária de tubérculos por vaso (PTV) e produção diária de tubérculos por tubérculo semeado (PDT), verificou- se variação independente do efeito principal População de Tiririca para as duas primeiras características em nível de 5 $\%$, e de $1 \%$ de probabilidade para PDT, pelo teste F (Tabela 9).

Tabela 9. Resumos das análises das variâncias para os dados de número de tubérculos por vaso (NTU), produção diária de tubérculos por vaso (PTV) e produção diária de tubérculos por unidade semeada (PDT) de tiririca C. rotundus L.

\begin{tabular}{|c|c|c|c|c|}
\hline \multirow{2}{*}{ Fontes de variação } & \multirow{2}{*}{ GL } & \multicolumn{3}{|c|}{ Quadrados Médios } \\
\hline & & NTU & PDV & PDT \\
\hline População de Tiririca (T) & 1 & $1640,25 *$ & $0,25 *$ & $0,099 * *$ \\
\hline Compactação (C) & 1 & $36,00 \mathrm{~ns}$ & $0,0054 \mathrm{~ns}$ & $0,002 \mathrm{~ns}$ \\
\hline $\mathrm{T} \times \mathrm{C}$ & 1 & $196,00 \mathrm{~ns}$ & $0,029 \mathrm{~ns}$ & $0,006 \mathrm{~ns}$ \\
\hline Resíduo & 12 & 304,12 & 0,046 & 0,006 \\
\hline Total & 15 & - & - & - \\
\hline
\end{tabular}

Na comparação das médias dos dados do número de tubérculos produzidos por vaso, constatou-se um maior valor quando foram semeados três tubérculos, os quais ao final do experimento produziram 134 novos tubérculos, contra 113 do tratamento com o semeio de dois tubérculos (Figura 5), o que é coerente, já que a produção de fitomassa de tubérculos foi maior no tratamento que produziu mais tubérculos.

Tal resultado corrobora com informações de Silva e Silva (2007) ao reportarem que cada tubérculo possui em média dez gemas e que em 60 dias cada um deles pode produzir até 126 novas unidades, com notável potencial de multiplicação, possivelmente devido a elevada concentração de auxina em seu interior. Adicionalmente, tem-se que a elevada infestação de $C$. rotundus numa área agrícola pode depreciar grandemente o valor da terra, motivo pelo qual o conhecimento adequado da biologia da espécie infestante com vistas a utilização de medidas adequadas de manejo é de suma importância.

Figura 5. Número de tubérculos produzidos por vaso pela espécie $C$. rotundus. L. As letras diferentes nas colunas indicam diferença significativa pelo teste $F(p=0,05)$

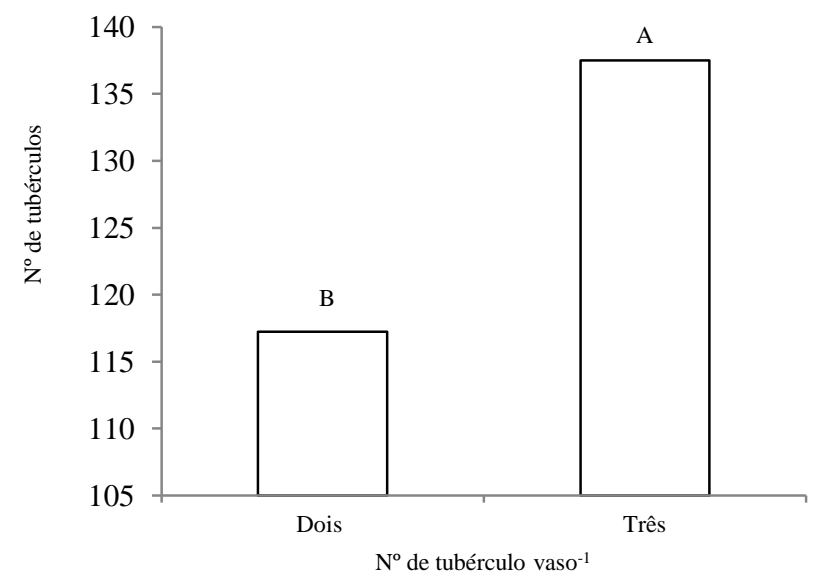

Com relação à produção diária de tubérculos por vaso (PTV), os maiores valores foram observados com o semeio de três unidades, independente da condição do solo, com ou sem compactação, em tal situação as plantas contidas em cada vaso produziram em média 1,7 tubérculos por dia (Figura 6). Todavia ao se verificar quantos tubérculos foram produzidos em média por cada unidade semeada (Figura 7), viu-se que ao final do experimento o semeio de dois tubérculos por vaso resultou numa maior produção unitária por unidade semeada, e cada tubérculo produziu por dia 0,72 novos tubérculos, o que significa dizer que a cada dez dias foram produzidos em média 7,2 novos tubérculos por cada tubérculo semeado, ou que ao longo do experimento cada tubérculo produziu 58 novas estruturas propagativas, enquanto no vaso onde foram semeados três tubérculos o valor médio foi de 45 tubérculos para cada unidade semeada, com uma produção média diária de 0,56, ou 5,6 tubérculos a cada dez dias.

Com tais resultados, fica evidente o notável potencial de disseminação de $C$. rotundus, e a grande necessidade de que medidas adequadas de manejo sejam tomadas com vistas a redução da proliferação de tal espécie em áreas agrícola, pois na prática tamanha agressividade representa grande empecilho ao controle eficiente, por métodos mecânicos quando o manejo se restringe a parte aérea, ou quando auxilia na disseminação e propagação assexuada da espécie, e no caso do método químico o herbicida de contato terão pouco ou nenhum efeito no controle de estruturas subterrâneas.

Figura 6. Produção diária de tubérculos por vaso de tiririca C. rotundus L.. As letras diferentes nas colunas indicam diferença significativa pelo teste $\mathrm{F}(\mathrm{P}=0,05)$

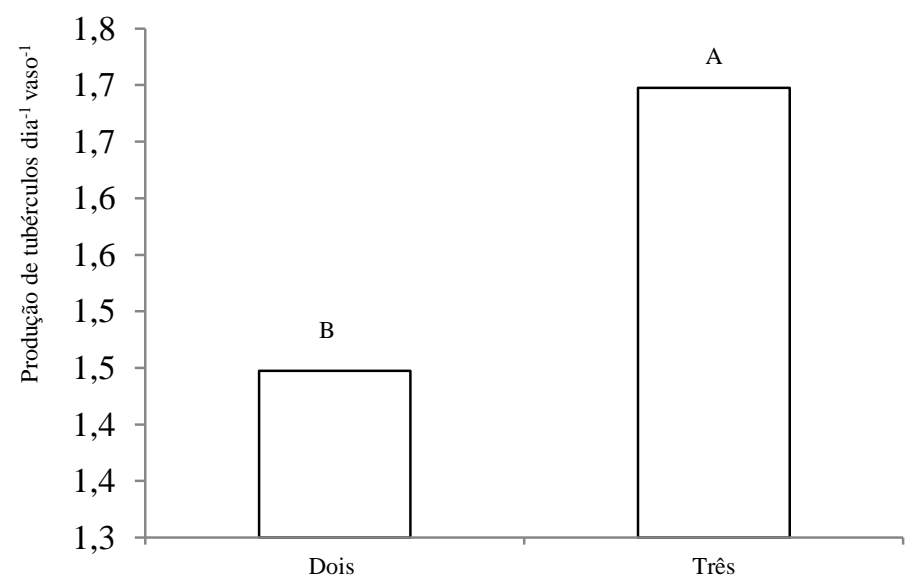

$\mathrm{N}^{\circ}$ de tubérculos pantados por vaso 
Figura 7. Produção diária de tubérculos por tubérculo plantado de tiririca $C$. rotundus L.. As letras diferentes nas colunas indicam diferença significativa pelo teste $\mathrm{F}(\mathrm{p}=0,05)$

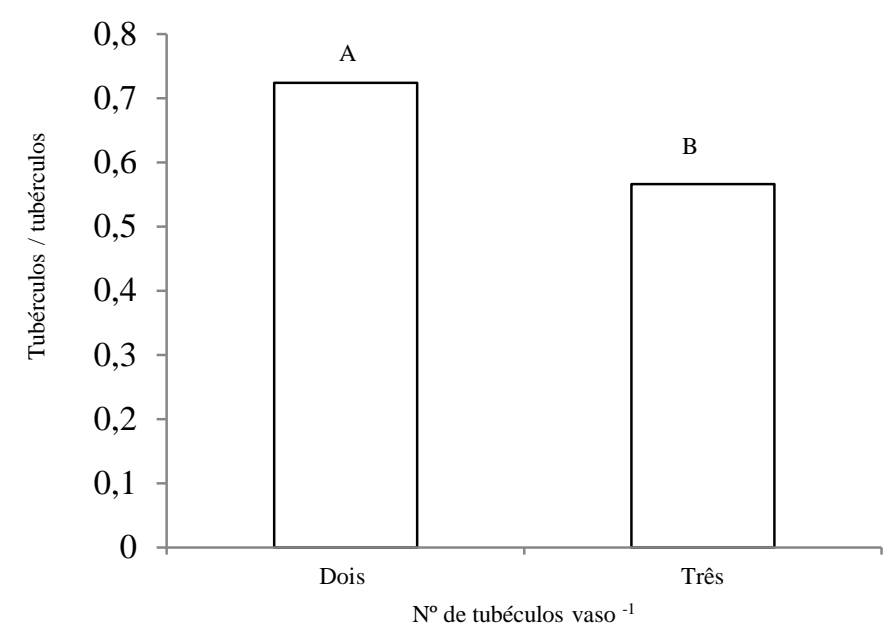

\section{CONCLUSÕES}

O plantio de dois ou três tubérculos por vaso resultou em elevada infestação de $C$. rotundus, o que provocou forte redução na concentração intercelular de $\mathrm{CO}_{2}$, fotossíntese e demais componentes fisiológicos, o que em última análise significa menor crescimento e acúmulo de fitomassa pela cultura;A espécie $C$. rotundus, possui notável poder de propagação, elevada relação raiz parte aérea, forte interferência sob a cultura do feijão-caupi, o que exige a realização de mais estudos visando à identificação e proposição de medidas de manejo eficientes, especialmente no Sertão paraibano, que se destaca na produção regional de feijão-caupi e as medidas de controle de plantas daninhas adotadas, em tal região, ainda são tradicionais e pouco eficientes.

\section{REFERÊNCIAS BIBLIOGRÁFICAS}

BEZERRA, A. A. C. Variabilidade e diversidade genética em caupi [Vigna unguiculata (L.) Walp.] precoce, de crescimento determinado e porte ereto e semi-ereto. 1997. $105 \mathrm{p}$. Dissertação (Mestrado) - Universidade Federal Rural de Pernambuco, PE. 1997.

CARDOSO, M. J.; RIBEIRO, V. Q. Desempenho agronômico do feijão-caupi, cv. Rouxinol, em função de espaçamento entre linhas e densidade de plantas sob regime de sequeiro. Revista Ciência Agronômica, V.37, p.102-105, 2006.

,Companhia Nacional de Abastecimento. Produção de Grãos.Brasília, 2013.Disponível em:< http: //www.conab.gov.br/OlalaCMS/uploads/arquivos/13_01_09_ 17_44_20_boletim_graos_janeiro_2013.pdf >. Acesso em: 23 dez. 2015 .

EMBRAPA MEIO NORTE. Cultivares. Teresina, 2008. Disponível em: <http://www.cpamn.embrapa.br/publicacoes/folders/2008/br1 7_gurgueia.pdf >.Acesso em $25 \mathrm{dez} .2015$.
EMBRAPA MEIO NORTE. Cultivares. Teresina, 2012. Disponível em: <http://www.cienciaparavida.com.br/ambientedenegocios/0307-cultivares.html_>. Acesso em 12 jan. 2016.

FREIRE FILHO, F.R.; LIMA, J.A.A.; RIBEIRO, V.Q. Feijão-caupi: avanços tecnológicos. Brasília: Embrapa Informação Tecnológica, 2005a. 519p.

FREITAS, F.C.L. et al. Interferência de plantas daninhas na cultura do feijão-caupi. Planta daninha [online]. 2009, vol.27, n.2, pp. 241-247. ISSN 1806-9681.

IBGE - Instituto Brasileiro de Geografia e Estatística. Levantamento Sistemático da Produção Agrícola. 2008.Disponível em: www.ibge.gov.br/home/estatistica/indicadores/agropecuaria/l spa. Acesso em: 23 dezembro de 2015.

MOUSINHO, F. E. P. Viabilidade econômica da irrigação do feijão-caupi no Estado do Piauí. 2005. 125 f. Tese (Doutorado em Irrigação e Drenagem). Piracicaba, Universidade de São Paulo. 2005.

MENDES, R. M. de S.; TÁVORA, F. J. A. F.; PITOMBEIRA, J. B. NOGUEIRA, R. J. M. C. Relações fonte-dreno em feijão-de-corda submetido à deficiência hídrica. Revista Ciência Agronomia, v.38, n.1, p.95-103, 2007.

OLIVEIRA, A. P. de; SILVA, V. R. F.; ARRUDA, F. P. de; NASCIMENTO, I. S. do; ALVES, A. U. Rendimento de feijão-caupi em função de doses e formas de aplicação de nitrogênio. Horticultura Brasileira, Brasília, V. 21, n.1, p.7780, 2003.

RAVEN, P.H., EVERT, R. F., EICHORN, S. E. Biologia Vegetal. Ed. Guanabara Koogan S.A., Rio de Janeiro, 2001, 906p.

SILVA, A. A. da; SILVA, J. F. da (Eds.). Tópicos em manejo de plantas daninhas. Viçosa: UFV, 2007, 367 p.: il.

TEÓFILO, E. M.; DUTRA, A. S.; PITOMBEIRA, J. B.; et al. Potencial fisiológico de sementes de feijão caupi produzidas em duas regiões do Estado do Ceará. Fortaleza, CE. Revista Ciência Agronômica, V. 39, n.3, p.443-448, 2008. 